\title{
Cost of low back pain: results from a national register study in Sweden
}

\author{
Gylfi Olafsson $^{1,2} \cdot$ Emma Jonsson $^{1} \cdot$ Peter Fritzell $^{3,4} \cdot$ Olle Hägg $^{5} \cdot$ Fredrik Borgström $^{1,2}$
}

Received: 16 March 2018 / Revised: 10 August 2018 / Accepted: 17 August 2018 / Published online: 28 August 2018 (c) The Author(s) 2018

\begin{abstract}
Purpose To estimate the societal costs of low back pain with/without radiating leg pain (LBP). LBP is a major burden in terms of both personal suffering and societal costs.

Methods Patients visiting healthcare providers with a LBP-diagnosis in the Western region of Sweden (Västra Götaland) in 2008-2011 were identified in national registers and an administrative patient database. Direct healthcare costs and indirect costs in terms of sick leave and early retirement were summarized over time periods called LBP episodes, starting with a LBP-related healthcare contact or work absence due to LBP and ended when 6 months had elapsed without any LBP-related healthcare contact or work absence.

Results The mean total cost per episode was estimated at $€ 2753$ with a mean duration of 51 days. There was a sharp increase in total cost the first month after the LBP episode started and a marked decrease from the second month. Total cost leveled off at a higher level during the 2 years after episode start compared with the 2 years before episode start. The total economic burden of LBP in Sweden including all LBP episodes that started in 2011 was estimated at $€ 740$ million, or $€ 78$ per capita. Conclusions LBP has an apparent impact on the overall resource use and work loss. The results indicate that there is a high short-term cost increase at the beginning of an LBP episode, but also that the costs decrease in the long term after the LBP symptoms have come to clinical attention.
\end{abstract}

Graphical abstract These slides can be retrieved under Electronic Supplementary Material.
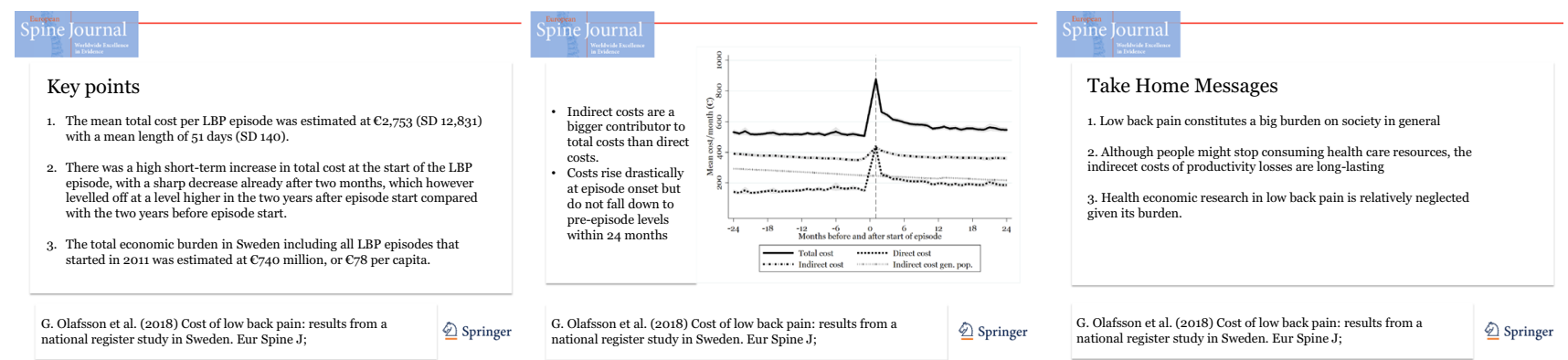

Keywords Cost of illness $\cdot$ Burden $\cdot$ Low back pain $\cdot$ Real-world data $\cdot$ Productivity loss $\cdot$ Sweden

\section{Introduction}

Electronic supplementary material The online version of this article (https://doi.org/10.1007/s00586-018-5742-6) contains supplementary material, which is available to authorized users.

Gylfi Olafsson

gylfi.olafsson@ki.se

Extended author information available on the last page of the article
Low back pain (LBP), with or without radiating pain, is a major burden in terms of both personal suffering and societal costs. According to the Global Burden of Disease study, LBP is the single largest contributor to years lived with disability [1]. In Sweden, the number of disability-adjusted life years lost to LBP increased by $0.065 \%$ annually over the last 25 years, according to the same study [2]. In addition, LBP 
was the largest diagnosis group in all paid short-term sick leave benefits in Sweden in 2001 [3]. LBP is very common, and at any given point in time, $15-30 \%$ of the population suffers from the disorder (prevalence), while $60-70 \%$ of the population has at some point in life suffered from the condition (incidence) $[4,5]$. Despite its considerable contribution to disability worldwide, the attention LBP has received has delivered less than optimal improvement for those affected on a group level.

Treatment of LBP can be quite complex, and although improvements have been made in the last decades, adopted treatment options and diagnostic procedures have not been shown to be universally effective [6]. Most patients with LBP receive conservative (non-surgical) care. However, when pain does not recede or is too intense, surgery can be considered in selected cases. Surgery is associated with high costs and a risk of complications but can improve pain and function considerably with appropriate patient selection. In addition to direct treatment costs, indirect costs, such as productivity loss and costs associated with care provided by relatives stack up to a high aggregated cost. Using a top-down approach (entailing that total national costs for illnesses are partitioned between different diagnoses), the burden of LBP in Sweden has been estimated at $€ 1860$ million in 2001 prices, where indirect costs accounted for $84 \%$ of total cost [7]. As a comparison, in 2014 prices, burden per capita per year has been estimated to approximately $€ 410$ in Europe and $€ 317$ in Australia [8, 9].

The objective of this study was to assess the societal burden of LBP in terms of direct costs (resource utilization) and indirect costs (losses to paid productivity), both on a patient level as well as the total burden on a Swedish national level.

\section{Materials and methods}

Materials and methods are described in more detail in the online-only supplement.

\section{Data sources and research database}

A research database was assembled by linking patient data on individual level from six Swedish national and regional registries as follows: (1) the administrative database VEGA from a regional authority in Western Sweden (Västra Götaland) with a total population of $1.6 \mathrm{M}$ inhabitants in 2015 , (2) the spine surgery register Swespine, (3) the Prescribed Drug Register, (4) National Patient Register (PAR) held by the National Board of Health and Welfare, (5) the LISA database from Statistics Sweden, and the (6) register of the Social Insurance Agency.

Patients were identified for inclusion in the database in two ways. All patients who visited health care during
2008-2012 as registered in VEGA with an ICD-10 code for LBP were identified along with patients who underwent surgery anywhere in Sweden during 2000-2012 as registered in Swespine. For all patients, data were extracted for the period 2000-2012. Linkage between data sources was conducted by Statistics Sweden using unique social security numbers and delivered the data de-identified.

\section{Study sample}

Patients were included in the study sample if they had a registered LBP-related cause for a healthcare visit or incident of sick leave/early retirement. In addition to LBP, also patients with radiating leg pain were included. Subjects were only included if they lived in Västra Götaland region, since data on outpatient visits were only available from the VEGA register.

A LBP-related cause was defined as all back pain or lumbar spinal disorders using the following ICD-10 codes: M43, other deforming dorsopathies; M46, other inflammatory spondylopathies; M47, spondylosis; M48, other spondylopathies; M51, other intervertebral disk disorders; M53, other dorsopathies, not elsewhere classified; and M54, lumbar pain. LBP due to tumor and trauma was not included.

\section{Analytical approach}

The burden of LBP was estimated using a prevalence-based bottom-up approach. This entails multiplying the number of incident cases within a defined time period with the corresponding cost. In this study, burden was calculated for LBP episodes, i.e., time periods of consecutive events close in time, all related to LBP.

\section{Resource use and costs}

\section{Outpatient and inpatient care}

Outpatient contacts (primary care and specialist care) were obtained from VEGA, and hospitalizations were obtained from the PAR register. The following healthcare visits occurring during an LBP episode were included in the cost calculations: general practitioner (GP), other physicians, nurse, physiotherapist, chiropractic, psychologist and other healthcare staff.

Outpatient visits and inpatient care were only counted and costed if they had a registered LBP-related ICD-10 code (see above). For some of the healthcare contacts, no explicit code had been entered to indicate the cause of the contact. In these cases, the contact was considered to be LBP-related if it occurred within a LBP episode. This applied to visits to physical therapists, rarely assigned a diagnosis, and other 
outpatient visits (e.g., assistant nurse, dietician) and hospitalizations without diagnosis code registered.

\section{Pharmaceutical costs}

Pharmaceuticals that were included in the analyses were pain medication, depression medications, muscle relaxants and anti-inflammatory. Because the drug prescription register does not contain diagnosis codes, it is not possible to determine the underlying cause for prescribing a drug. All above drugs prescribed within an LBP episode were therefore included in the calculations.

\section{Indirect costs}

Indirect costs were measured in terms of losses to paid productivity. The absence from work was assumed to be LBP related if it had an explicit LBP-related ICD-10 code (as defined above), or if it had any other code, and the work absence period was ongoing or started during an LBP episode. Productivity loss was valued using the human capital approach, assuming that indirect cost of each day of absence corresponds to the average gross daily wage (with payroll taxes added) [10].

Changes in the social security system and other structural changes have major impact on the use of social benefits [11]. For example, the so-called rehabilitation chain implemented by the Swedish government in 2008 has been shown to have a diminishing effect on sick leave [11]. Therefore, a control group consisting of aggregated data from the total Swedish population [12] was included as a reference when looking at trajectory of indirect costs.

\section{Unit costs and year of pricing}

Unit costs for healthcare resources were collected from Västra Götaland's and other Swedish county councils' regional pricelists where unit cost for a resource item was not available from Västra Götaland (see online supplement). Unit costs for LBP surgeries and surgical complications were derived using a price list from a reimbursement system in Stockholm county council and a DRG price list from Västra Götaland [13, 14] and include all relevant direct costs in relation to operations and hospital stay. The average gross daily wage (adding payroll taxes) used to calculate indirect costs due to sick leave and early retirement was collected from Statistics Sweden [15]. Costs were inflated to the price level of 2016 using consumer price index from Statistics Sweden. Costs are presented in Euros $(€)$, converted at the average annual exchange rate for 2016 of 9.47 Swedish Krona per Euro.

\section{Software and research ethics}

Data management was done using MySQL, and statistical analyses were executed using Stata 14 software package. The study was approved by Stockholm ethics vetting committee, decision 2013/2225-31/5. All use of data was in accordance with the Swedish law on personal data, Personuppgiftslagen, 1998:204.

\section{Results}

\section{Study sample}

A total of 159,924 LBP episodes in 129,973 individuals were identified over a period of 4 years (Table 1). The mean age at episode start was 52.6 years, and $58 \%$ were women. The majority had 10 or more years of schooling $(61 \%)$ and were born in the Nordic countries (81\%). The average length of an LBP episode was 51 days (SD 140). The proportion of Västra Götaland's population who had at least one LBP episode increased from $2.0 \%$ in 2008 to $2.9 \%$ in 2011.

\section{Resource utilization and cost per patient}

Table 2 presents a summary of resource utilization and cost per patient by cost category. The mean total cost for a LBP episode was estimated at $€ 2753$. Of total cost, $67 \%$ was related to indirect costs (sick leave and early retirement). The largest healthcare cost category was visits to physician, accounting for $11 \%$ of total costs. The smallest cost category was other outpatient visits, i.e., visits other than to physician and physiotherapist, which accounted for $1 \%$ of the total costs. The distribution of costs was highly skewed to the left, indicating that most of costs emerged from a minority of the patients, which is shown by that the median costs are markedly lower than the mean.

\section{Cost trajectories}

Figure 1 shows the trajectory of direct, indirect and total costs per month for 24 months prior and 24 months after start of the first observed LBP episode (including all healthcare resource use and work loss, considered LBP related or not). The cost levels were apparently affected by the LBP episode start, with a marked short-term increase in costs at the first month after episode start. In the second month after episode start, cost levels were noticeably lower compared to the first month. Following the second month, costs continued to gradually decrease. However, 
Table 1 Descriptive statistics

\begin{tabular}{|c|c|c|}
\hline Variable & Value & $\begin{array}{l}95 \% \\
\text { confidence } \\
\text { interval }\end{array}$ \\
\hline Number of patients & \multicolumn{2}{|l|}{129,973} \\
\hline Number of episodes & \multicolumn{2}{|l|}{159,924} \\
\hline \multicolumn{3}{|c|}{ Number of patients with at least one LBP episode per year (\% of Västra Götaland's population) } \\
\hline 2008 & \multicolumn{2}{|l|}{$30,506(2.0 \%)$} \\
\hline 2009 & \multicolumn{2}{|l|}{$35,906(2.3 \%)$} \\
\hline 2010 & \multicolumn{2}{|l|}{$43,562(2.8 \%)$} \\
\hline 2011 & \multicolumn{2}{|l|}{$46,089(2.9 \%)$} \\
\hline Age at episode start & 52.6 & $(52.4-52.7)$ \\
\hline Females $(\%)$ & $58.1 \%$ & $(57.9-58.3)$ \\
\hline Episode length (days) & 51.4 days & $(50.7-52.0)$ \\
\hline \multicolumn{3}{|l|}{ Education level } \\
\hline $0-9$ years & $38.5 \%$ & $(38.2-38.7)$ \\
\hline 10-13 years, high school & $42.5 \%$ & $(42.2-42.7)$ \\
\hline $13+$ years, undergraduate & $18.6 \%$ & $(18.4-18.8)$ \\
\hline Postgraduate & $0.4 \%$ & $(0.4-0.5)$ \\
\hline \multicolumn{3}{|l|}{ Country of birth } \\
\hline Nordic countries & $81.1 \%$ & $(80.9-81.3)$ \\
\hline Other Europe & $8.2 \%$ & $(8.1-8.3)$ \\
\hline Outside of Europe & $10.7 \%$ & $(10.6-10.9)$ \\
\hline
\end{tabular}

total costs remained on a higher level in the 2 years after episode start compared with the 2 years before episode start.

Indirect costs decreased during the years leading up to episode start, which corresponded to decreased indirect costs in the total Swedish population. This indicates that changes in the social security system (e.g., the so-called rehabilitation chain implemented in 2008) and/or structural changes in the Swedish economy have affected the use of sick leave benefits.

\section{Societal cost of LBP in Sweden}

If the LBP population in Västra Götaland in terms of incidence and demographic composition is representative for the whole of Sweden, the number of LBP episodes that started in 2011 in Sweden was calculated at 274,773. By multiplying this number with the mean cost per LBP episode, the societal cost could be estimated at $€ 740$ million, or $€ 78$ per capita (Table 3). Sixty-six percentage of the total cost could be related to work absence.

\section{Discussion}

LBP is a well-documented health problem and a leading cause of disability and work absence $[3,17,18]$. The current study adds details to the existing literature about the timely effects that LBP has on the healthcare system and society at large in Sweden. Using a representative Swedish region constituting $15 \%$ of the total population in the country, an average LBP episode was estimated at 51 days with an average total cost of $€ 2753$. When extrapolating the results to the whole of Sweden, the yearly national societal cost of LBP was estimated at $€ 740$ million in all LBP episodes that started during 2011.

This study did not investigate changes in the national burden of LBP over time. The proportion of the population who had at least one LBP episode increased from $2.0 \%$ in 2008 to $2.9 \%$ in 2011 , as shown in Table 1 . This is worrying and in line with the general literature, although the specific reasons for this dramatic increase is unknown [2, 19]. A cost-of-illness study gives no direct guidance of how resources should be allocated to improve efficiency, but can give information about the total societal burden which can be important when determining what attention and awareness the disease should be given in, for example, public health interventions. Another important aspect is that cost-of-illness studies could also provide information about who bears the burden of disease-be it the healthcare sector, the patients or the employers.

The high level of cost of LBP and its observed rise in Sweden are similar in many other countries, especially in the western part of the world. This creates large potential for savings if it were possible to reduce back pain, which has proven to be elusive. 
Table 2 Resource utilization and costs ( $€$ ) per LBP episode stratified by cost category between 2008 and 2011

\begin{tabular}{|c|c|c|c|c|c|c|c|c|}
\hline \multicolumn{2}{|l|}{ Category } & Mean & SD & Median & $\begin{array}{l}\text { Interquartile } \\
\text { range (IQR) }\end{array}$ & Min & Max & $95 \% \mathrm{CI}$ \\
\hline \multicolumn{9}{|l|}{ Resource utilization } \\
\hline \multicolumn{2}{|l|}{ Pharmaceuticals (defined daily doses ${ }^{\mathrm{a}}$ ) } & 81.8 & 295.9 & 10 & 50 & 0 & 16,879 & $80.3-83.2$ \\
\hline \multicolumn{2}{|l|}{ LBP surgeries (incl. re-interventions) } & 0.02 & 0.2 & 0 & 0 & 0 & 7 & $0.02-0.02$ \\
\hline \multicolumn{2}{|c|}{$\begin{array}{l}\text { Non-surgical-related inpatient care (days } \\
\text { hospitalized) }\end{array}$} & 0.3 & 2.8 & 0 & 0 & 0 & 252 & $0.3-0.3$ \\
\hline \multicolumn{2}{|l|}{ Outpatient physician visits } & 1.5 & 2.1 & 1 & 0 & 0 & 101 & $1.5-1.6$ \\
\hline \multicolumn{2}{|l|}{ Physical therapy visits } & 1.4 & 6.7 & 0 & 0 & 0 & 352 & $1.3-1.4$ \\
\hline \multicolumn{2}{|l|}{ Other outpatient visits } & 0.2 & 1.5 & 0 & 0 & 0 & 177 & $0.2-0.2$ \\
\hline \multicolumn{2}{|l|}{ Work absence—sick leave (days) } & 7.6 & 58.6 & 0 & 0 & 0 & 1840 & $7.3-7.9$ \\
\hline \multicolumn{2}{|l|}{ Work absence—early retirement (days) } & 4.0 & 45.6 & 0 & 0 & 0 & 1819 & $4.8-5.2$ \\
\hline Category & Mean & SD & Median & $\begin{array}{l}\text { Interquartile } \\
\text { range (IQR) }\end{array}$ & Min & Max & $95 \% \mathrm{CI}$ & $\%$ of total cost \\
\hline \multicolumn{9}{|l|}{ Costs $(€)$} \\
\hline Pharmaceuticals & 38 & 208 & 6 & 21 & 0 & 26,306 & $37-39$ & 1 \\
\hline LBP surgery & 244 & 1951 & 0 & 0 & 0 & 61,432 & $234-253$ & 9 \\
\hline Non-surgical-related inpatient care & 227 & 2069 & 0 & 0 & 0 & 237,121 & $216-237$ & 8 \\
\hline Outpatient physician visits & 308 & 505 & 155 & 155 & 0 & 17,984 & $306-310$ & 11 \\
\hline Physical therapy & 86 & 422 & 0 & 0 & 0 & 22,176 & $83-88$ & 3 \\
\hline Other outpatient visits & 15 & 144 & 0 & 0 & 0 & 18,241 & $15-16$ & 1 \\
\hline Direct costs & 917 & 3430 & 174 & 217 & 5 & 267,460 & $900-934$ & 33 \\
\hline Work absence—sick leave & 1109 & 8556 & 0 & 0 & 0 & 268,640 & $1067-1151$ & 40 \\
\hline Work absence_-early retirement & 727 & 6661 & 0 & 0 & 0 & 265,574 & $694-760$ & 26 \\
\hline Indirect costs & 1836 & 11,241 & 0 & 0 & 0 & 307,914 & $1781-1891$ & 67 \\
\hline Total costs & 2753 & 12,831 & 196 & 309 & 60 & 490,819 & $2690-2816$ & 100 \\
\hline
\end{tabular}

Values may not sum up to $100 \%$ due to rounding

${ }^{a}$ Defined daily doses are a statistical measure of drug consumption defined by the WHO and is the assumed average maintenance dose per day for a drug used for its main indication in adults [16]

Fig. 1 Mean indirect, direct and total cost per patient and month during 24 months before and 24 months after the start of the first LBP episode. The dotted line shows the indirect cost per month in the total Swedish population. Includes both LBPrelated and non-LBP-related costs. Shaded areas show 95\% confidence intervals of the means

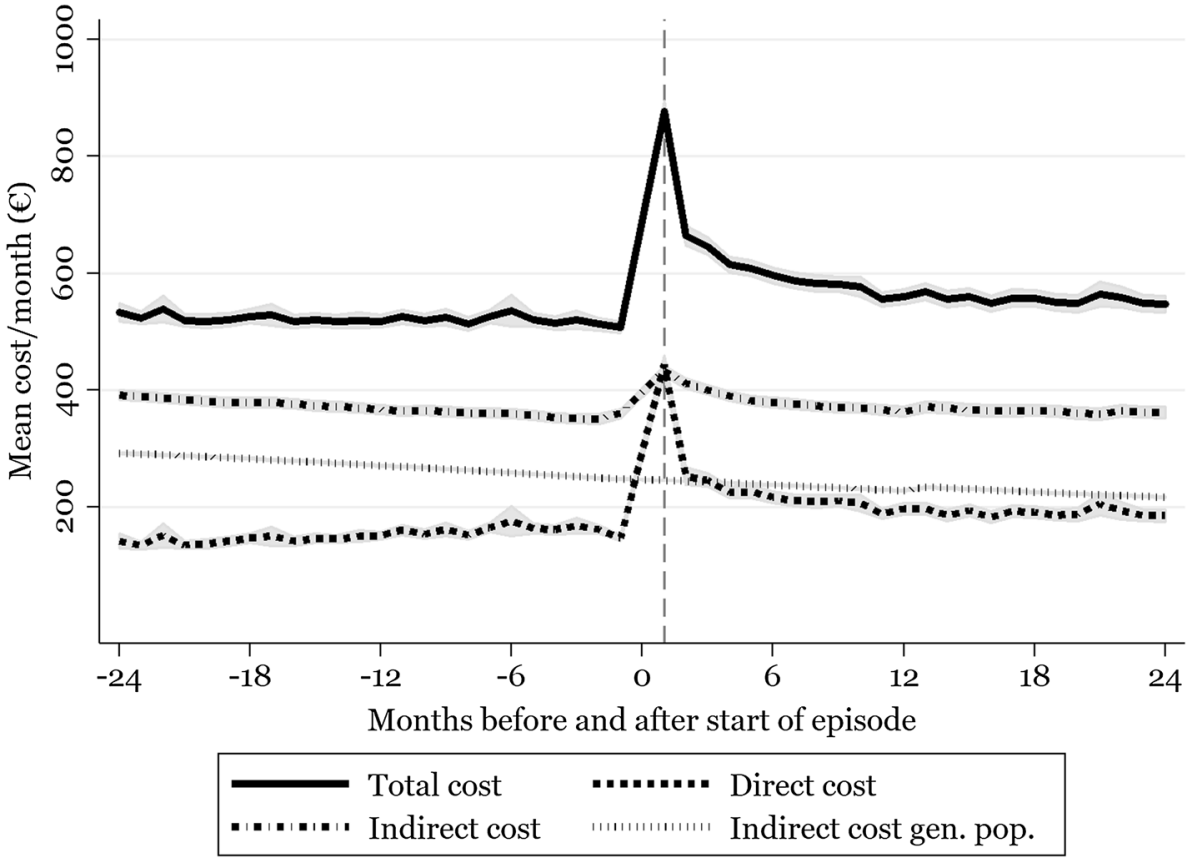


Table 3 Mean national cost (million $€$ ) of LBP episodes started in 2011 in Sweden

\begin{tabular}{lcc}
\hline Category & $\begin{array}{l}\text { Million EUR } \\
(€ \text { million })\end{array}$ & Per capita $(€)$ \\
\hline Pharmaceuticals & 10 & 1 \\
LBP surgery & 68 & 7 \\
Non-surgical-related inpatient care & 122 & 13 \\
Medical visits & 94 & 10 \\
Physical therapy & 25 & 3 \\
Direct costs & 252 & 27 \\
Work absence-sick leave & 337 & 36 \\
Work absence—early retirement & 151 & 16 \\
Indirect costs & 488 & 51 \\
Total costs & 740 & 78 \\
\hline
\end{tabular}

The estimated cost per capita of $€ 78$ in 2011 in the current study can be compared to previous estimates. According to a systematic review of international cost-of-illness studies of LBP, the total cost per capita has ranged from $€ 48$ to $€ 2874$. Two Swedish studies were included in this review, in which both estimated considerably higher costs per capita compared with our study. Ekman et al. [7] estimated the cost in 2001 at $€ 209$ per capita ( €250 in 2016 year prices). In this study, direct costs were similar to our estimate, while indirect costs were nearly three times higher. An explanation might be that the rate of sick leave in the whole Sweden was markedly higher around the years 2001-2002 (approximately 21 days per insured individual and year) compared with 2010 (approximately 7 days per insured individual and year) [11]. This strengthens the hypothesis that general trends in sick leave/early retirement in the society have an impact on the total costs that can be related to LBP. A Swedish study from 2005 estimated the total cost per capita to $€ 381$. This study included only individuals who were on sick leave for at least 1 month, and in working age, which makes the indirect costs, and thereby total, higher compared with our study.

This study is not without limitations. The calculations on a national level assume that the LBP population in the region of Västra Götaland in terms of incidence and demographics is representative for the whole Sweden. Further, the study lacked some variables that might be of interest. No direct information was available on diagnostic imaging as these are not reported separately in the available data, nor was cost due to durable medical equipment available separately. This will bias the cost downwards. We did not have data on sick leaves shorter than 14 days. No data on individual level exists on presenteeism (i.e., reduced work capacity when working) or the inability to perform household work. Therefore, the indirect cost of work absence may be to some extent underestimated. Further, out-of-pocket costs for over-the-counter drugs are not included. Another variable of interest is paid home help. Fritzell et al. estimated the cost of family support (housekeeping) for patients randomized to surgery or non-surgical treatment for chronic low back pain, reaching estimates between $€ 13$ and 16,000 over 2 years (2016 prices) [20]. This is a potential downward bias in our cost estimates. Our bottom-up approach relies on coding or context for relating costs to LBP. This might underestimate the costs, due to, for example, lack of coding, costs falling outside the reach of our data set, and due to secondary effects of LBP on other health problems. Due to the diffuse nature of LBP, and common inaccuracies in initial diagnoses, a very broad definition of LBP was used, one for which back pain or lumbar spinal disorders might be a better name.

In conclusion, the mean cost per LBP episode/patient was estimated at $€ 2753$ and the total economic cost of all episodes that started in 2011 was estimated at $€ 739$ million ( $€ 78$ per capita). The results indicate that the healthcare contact at the start of LBP episode has an impact on the total resource use, including work loss, but that the cost levels are not entirely restored to pre-episode levels. This study gives no direct guidance of how resources should be allocated to improve efficiency. However, the high costs, upward trends, and the fact that costs fall slowly pre-episode costs if at all, indicate the importance of the consequences of LBP both for the individual patients and the society.

Acknowledgements The involvement of GO, EJ and FB in the study was financed with an unrestricted grant from Medtronic.

\section{Compliance with ethical standards}

Conflict of interest None of the authors has any potential conflict of interest.

Open Access This article is distributed under the terms of the Creative Commons Attribution 4.0 International License (http://creativeco mmons.org/licenses/by/4.0/), which permits unrestricted use, distribution, and reproduction in any medium, provided you give appropriate credit to the original author(s) and the source, provide a link to the Creative Commons license, and indicate if changes were made.

\section{References}

1. Murray CJ, Lopez AD (2013) Measuring the global burden of disease. N Engl J Med 369(5):448-457

2. Global Burden of Disease study 2015 (2015) GBD Compare Viz Hub. Institute for Health Metric and Evaluation, University of Washington. https://vizhub.healthdata.org/gbd-compare/embed \#settings=10e29822701396f1813ef3213edaa1118aad4e13

3. Social Insurance Agency (Försäkringskassan) (2002) Vad kostar olika sjukdomar? -sjukpenningkostnader fördelade efter sjukskrivningsdiagnos 
4. Hoy D et al (2010) The epidemiology of low back pain. Best Pract Res Clin Rheumatol 24(6):769-781

5. Statens beredning för medicinsk och social utvärdering (2001) Ont i ryggen, ont i nacken

6. Buchbinder R et al (2013) Placing the global burden of low back pain in context. Best Pract Res Clin Rheumatol 27(5):575-589

7. Ekman M, Johnell O, Lidgren L (2005) The economic cost of low back pain in Sweden in 2001. Acta Orthop 76(2):275-284

8. Maniadakis N, Gray A (2000) The economic burden of back pain in the UK. Pain 84(1):95-103

9. Walker BF, Muller R, Grant WD (2003) Low back pain in Australian adults: the economic burden. Asia Pac J Public Health 15(2):79-87

10. van den Hout WB (2010) The value of productivity: humancapital versus friction-cost method. Ann Rheum Dis 69(Suppl 1):i89-i91

11. Social Insurance Agency (Försäkringskassan) (2014) Analys av sjukfrånvarons variation. www.forsakringskassan.se

12. Social Insurance Agency (Försäkringskassan) (2017) Number of sick leave and early retirement days per region and age group 2000. https://www.forsakringskassan.se/statistik/statistik_och_ analys2/Sjuk/sjuk_rehabiliteringspenning
13. Västra Sjukvårdsregionen Samverkansnämnden (2016) Utomlänspriser 2016 För vårdtjänster enligt samverkansavtal om hälso- och sjukvård inom Västra sjukvårdsregionen som gäller från 2016-01-01

14. Hälso- och sjukvårdsförvaltningen Stockholms Läns Landsting (2013) Förfrågningsunderlag enligt LOV Vårdval Ryggkirurgi

15. Statistics Sweden (2015) Average monthly wage. http://www.stati stikdatabasen.scb.se/

16. WHO Collaborating Centre for Drug Statistics Methodology (2017) DDD definition and general considerations

17. Hoy D et al (2014) The global burden of low back pain: estimates from the Global Burden of Disease 2010 study. Ann Rheum Dis 73(6):968-974

18. Social Insurance Agency (Försäkringskassan) (2011) Vad kostar olika sjukdomar i sjukförsäkringen?

19. Hoy D et al (2012) A systematic review of the global prevalence of low back pain. Arthritis Rheum 64(6):2028-2037

20. Fritzell P et al (2004) Cost-effectiveness of lumbar fusion and nonsurgical treatment for chronic low back pain in the Swedish Lumbar Spine Study: a multicenter, randomized, controlled trial from the Swedish Lumbar Spine Study Group. Spine 29(4):421434 (discussion Z3)

\title{
Affiliations
}

\author{
Gylfi Olafsson $^{1,2} \cdot$ Emma Jonsson $^{1} \cdot$ Peter Fritzell $^{3,4} \cdot$ Olle Hägg $^{5} \cdot$ Fredrik Borgström $^{1,2}$ \\ Quantify Research, Stockholm, Sweden \\ 5 Spine Center Göteborg, Göthenburg, Sweden \\ 2 LIME/MMC, Karolinska Institutet, Stockholm, Sweden \\ 3 Capio St Göran, Stockholm, Sweden \\ 4 Futurum Academy, Jönköping, Sweden
}

